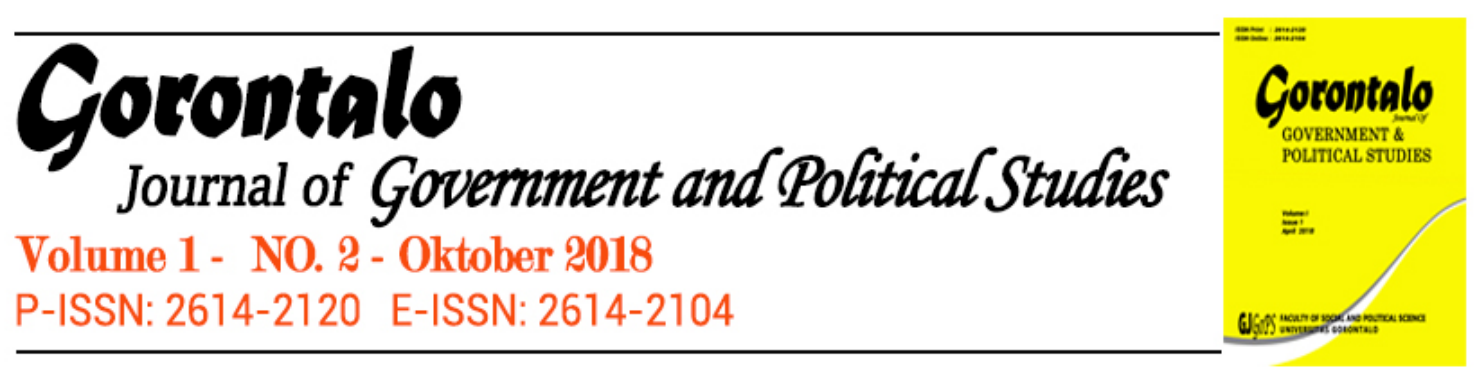

\title{
Analysis of Indonesian Public Diplomacy Through Friends of Indonesia: Fellowship for Future Ambassadors Program 2018
}

\author{
Muhaimin Zulhair Achsin \\ Khairunnisa Nadhifa \\ Program Studi Ilmu Pemerintahan FISIP Universitas Brawijaya \\ J1. Veteran, Malang, Jawa Timur, Telp. (0341) 575755, ext. 121
}

\begin{abstract}
The aim of this writing is to understand the Indonesian Public Diplomacy and how it works through one of the implemented program which is Friends of Indonesia: Fellowship for Future Ambassadors 2018 carried out under the Ministry of Foreign Affairs of Indonesia. In addressing to this subject, this writing will analyze the implementation and the impact of Public Diplomacy by the Ministry of Foreign Affairs of Indonesia with the concept of Mark Leonard's three dimensions of Public Diplomacy, specifically in the dimension of Relationship Building in order to see the picture of Indonesian Public Diplomacy in the Friends of Indonesia program.
\end{abstract}

Keywords: Friends of Indonesia; Public Diplomacy; Relationship Building.

\section{INTRODUCTION}

\subsection{Introduction to Public Diplomacy}

In brief historical review, public diplomacy has always been usedfor centuries by state actors even before the break out of 9/11 in the United States of America, where suddenly the whole global attention shifted to the public diplomacy of "War On Terror" reign, resulted in shifting the global aspect of perspectives between the West and the Middle East countries. Jan Melissen(2005: 3)stated that in early seventeenth century France went to much greater lengths in remoulding their country image abroad than other European powers, and they put enormous effort into managing their country's reputation. Others countries followed suit, such as Turkey in the aftermath of the Ottoman empire. Kemal Attaturk changed the face of his country and identity.

Nevertheless, Public Diplomacy was a form of formal technical instrument of foreign politics in order to shape image of countries' perspective in general all according to their own interest of view. For instance, during the First World War in which the birth of International Relations grew to the study of states relations' heavily implies on the subject of public diplomacy as one of soft power's tool used by the states to shape perspectives to the world. As of for now in the current global era, 

Public Diplomacy is used as a common instrument by states and non-state actors to be used in order to seek or promote interest through understanding and influence through various form of activities to win "hearts and minds" of foreign audiences.

In general form of understanding, according to Joseph Nye (2008: 108), public diplomacy is an important tool in the arsenal of smart power (combining hard and soft power), but smart public diplomacy requires an understanding of the role of credibility, self-criticism, and the role of civil society in generating soft power.Soft power is the ability to affect others to obtain the outcomes one wants through attraction rather than coercion (sticks) or payment (carrots) and power itself is the ability to affect others to obtain the outcomes you want. Furthermore, Nye stated that promoting positive images of one's country is not new, but the conditions for projecting soft power have transformed dramatically in recent years. Politics in an information age "may ultimately be about whose story wins" (Arquila and Ronfeldt 1999 cited in Nye 2008: 100).

The many examples of the common implementation of public diplomacy varied from different activities such as exchange of culture, international fairs, music and food festivals, films and et cetera. Through these types of activities, the states were able to create a bridge between other countries in order to show them a new perspective from the representative country in an exchange of public opinion and this is one of the things that pushes the effects towards other aspects to improve. One of them is to plant an image from one country to another that will allow them to build relation in better further condition than before.

Application of public diplomacy traditionally involves the leaders of state-tostate interaction in government-to-government exchange however the latter interaction can be done through government leaders to the people in government-topeople contact. The form of public diplomacy allows to improve the implementation and opportunities therefore in the contemporary understanding, the definition transforms as the process of direct contact of actors from one state to another in order to achieve interest and to share values they represented.

If we were to describe Indonesia's form of Public Diplomacy in general, there are several factors that created the image of Indonesia through public diplomacy that involves these several factors. First is that Indonesia being one of the country with the most populated Muslims in the world, allows them the possibility to have close relations with other Muslim countries such as in Middle East. Second, Indonesia is a democratic country therefore the diplomatic activities conducted by the country involves in spreading the democratic values and principles (example freedom, dignity, decolonialization 1955 Bandung Conference) to other countries. Third, Indonesia builds the image as one of the country to have the highest economic capabilities in Southeast Asia in the development of market, tourism and foreign investments.

The strategic situation of Indonesia as a middle power in Southeast Asia creates the image of Indonesia as a potential country to be able to influence their relations with other countries in Asia or even on broader international scale. Indonesia's capabilities as a middle power can be looked through the aspects of politics, 
economy, security, military, as well as social-culture, which are great potentials to be used as diplomatic instruments to secure the image of Indonesia's foreign politics and policies. On the other side, Indonesia proves to be able to win the hearts of other countries in international scale through soft power especially in the case of public diplomacy.

The focus of public diplomacy implemented by Indonesia, specifically handled by the Indonesia's Ministry of Foreign Affairs (MoFA), highlights on the instruments of political and cultural exchange. Indonesia's best strategy in winning the hearts of other countries is through exchanges of ideas, values, and culture resulting in influencing actors in the exchange. On that account, Indonesia continue to work by the use of both state and non-state actors in the activities. One of the well mentioned works by the MoFA is the establishment of the annual Bali Democracy Forum in order to share the democratic principles in maintaining Indonesia's image as a democratic country in the international level. Afterwards in the aspect of culture, Indonesia was able to showcase exchanges in cultural festivals abroad through Indonesian embassies, film discussions and offering art scholarship to foreigners to learn Indonesian traditional arts and language.

One of the newest programset by the MoFA is the Friends of Indonesia: Fellowship for Future Ambassadors 2018 (FOI). The program was created to invite 10 young diplomats from 10 different countries to visit Indonesia for 2 weeks in order to learn about Indonesia through people-to-people contact, furthermore to bond closer with the diplomats from 10 different countries in understanding Indonesia intimately. In addition, the program hopes to leave an impression from the invited diplomats about Indonesia and uses this opportunity to build bridges of diplomatic context in hopes to remind of Indonesia once they had achieved success in their career in the future. This journal is written to discuss and analyze the implemented program of FOI 2018 as a form of public diplomacy process in Indonesia.

The several previous works that particularly explained Indonesian public diplomacy were Azyumardi Azra (2015) Indonesia's middle power public diplomacy: asiaand beyond, which explained the pattern of Indonesia's public diplomacyfrom Sukarno to post-Suharto era, Rizal Sukma(2011), Soft Power and Public Diplomacy: The Case of Indonesia, and Sukawarsini Djelantik (2008), Theory and practice of Indonesian diplomacy and foreign relations. However, this paper offers a novelty regarding newest program of Indonesia's public diplomacy namely Friends of Indonesia.

\section{RESEARCH METHODS}

\subsection{Type of Research}

This following research is a descriptive-analytic research type with qualitative attributes. The analysis of this research uses the concept by Mark Leonard's three dimensions of public diplomacy (2002) of News Management, Strategic Communication, and Relationship Building.

\subsection{Location of Research}


This location of this research is at the Indonesian Ministry of Foreign affairs in Jakarta as well as following the program of Friends of Indonesia held in Bandung as well as Bali.

\subsection{Data Gathering}

This research collected both of primary and secondary data. The technique of data gathering used in this research is through interviewsas well as documentation. In-depth interview is a data gathering technique conducted where the researcher will ask directly to the primary sources such as the staff of Ministry of Foreign Affairs, the Director from the Directorate of Public Diplomacy, and the 10 diplomats from the foreign countries. Documentation is a form of data gathering technique where the researcher documents all of the primary and secondary sources based on acquired data.

\subsection{Data Analysis}

Data analysis of this following research is through qualitative analysis thoughmanagement of data, reduction of data, data interpretation based on findings, validity check, and conclusion in the end of the analysis.

\section{RESULT AND DISCUSSION}

The MoFA of Indonesia is solely responsible for all of the activities related to international relations on a formal legal basis from the government as an institution to carry out national duties and responsibilities. Public diplomacy under Indonesia's MoFA can be described as festive as the Directorate of Public Diplomacy, a specific department that is responsible for all of Indonesia's public diplomacy duties, regularly host events, programs and offer scholarships in order to maintain the bridge between Indonesia and the rest of the world.

One word to uphold by the Directorate of Public Diplomacy in maintaining the bridge of relationship is to call these countries "the best friends of Indonesia" in order to keep the perspective that in gaining favors with foreign actors. Generally, the principles of activities carry out by this department is based on achieving partnership, networking, promotion, dissemination and people-to-people contact. So all of the activities carried out by the MoFA needs to be based on these principles because it underlines the main point and mission of Indonesia to carry out public diplomacy instruments in the field.

By the writer's analysis on the job performance carried out by MoFA in managing the public diplomacy, there are several positive and negative points during the process of work. First and foremost, towards the positive box; there are several good points in managing the events and programs to be carried out throughout the year. Regular meets and discussion as well as deep research helps to enrich the events and programs to become more adequate and compelling which draws more exchange of ideas formally well. There is actual good intention delivered by the Directorate of Public Diplomacy as they carry out their tasks by dividing into 5 different categories in their sub-directorates which are Politics and Security, Economy and Development, Actual and Strategical Issues, Social and Culture, and Empowerment of Indonesian Citizens Abroad. The division of these are based on the 
missions each sub-directorate carries out for their goals, resulting in extensively accomplishing Indonesia's public diplomacy achievements in short amount of time throughout the year which counts as an impressive note due to their lack of staff.

On a more negative points, in a realistic view in carrying out huge amount of events and programs to accomplish in a year-term, the preparation was handled out short and lacking. The writer was able to take note on how the management in the institution lacks staff therefore pressures the deadline works and resulting staff to not have the chance to plan out for the long term post-events and programs during the meetings and research. If we were to draw a conclusion, the whole picture creates the notion that the institution progress fairly well in preparation and the implementations but not so much on the following up afterwards.

This draws the understanding that MoFA was not able to create longer term of continuous contact after the event and programs ended, lacking in creating further communication and thus losing the opportunity to strengthen the bridges of actors involved. This creates Indonesia's public diplomacy as merely simple tool or reason to be used in carrying out the extensive events and programs but after the implementation carried out, there are no further progress on the post-activities, declining the chance of creating deeper relationship through communication between the actors. If the MoFA were able to carry out this plan of ongoing communication then there would be changes of gaining favors from foreign ministers in other countries in case of emergencies or aid in general for example in economic or security matters when Indonesia is being challenged in the international scale, there would be allies to back up Indonesia in the field.

Bringing on the attention towards the program FOI 2018. In brief review, the program FOI 2018 was designed to fulfill the mission principle of people-to-people contact from the institution. FOI program involved 10 young diplomats from different countries which are from Bangladesh, Fiji, Guyana, Cambodia, Japan, Mexico, Nigeria, Papua New Guinea, and Portugal. The initiative for this program was proposed to give positive opportunities for the young diplomats and Indonesia. The programcarried out on $18^{\text {th }}$ - $26^{\text {th }}$ of July 2018 , held on three different locations which were in Jakarta, in focusing political and security aspects by visiting Indonesia's MoFA, independent media office and the UN Peacekeeping Training Centre. The second location was in Bandung, focusing on economic industries and Museum of Conference Asia-Africa. The last location is in Denpasar, focusing on social and cultural aspects of Indonesia from different tourist attractions of Bali. By the end of this program, FOI was able to create close relationship between the young diplomats and Indonesia as they are attentively interest in various sectors.

Judging by the data the writer was able to gather, the job performance of this specific program went fairly well in carrying out the mission of people-to-people contact by the foreign young diplomats to Indonesia actors whether they might be officials from the MoFA or the non-state actors from the representative sectors they come in contact with. The preparation for the program had been short by meetings and discussion filled with research and communication through the embassies of the representative countries, the program was able to place a tight schedule for the implementation to be carried out. 
Even though the program lasted only for 2 weeks, it was able to create the impact greatly on the young diplomats who participated. The young diplomats who participated from this program acts as the representative from their own respective countries however they also act as intel by gathering many information as possible so that they were able to analyze in their own perspective and carry out their information as personal agenda towards their own foreign ministries from their home countries. The information they wrote in their personal agenda may be able to become useful for their own information-gathering research as they explore more of Indonesia's capabilities to their own benefits. Not only that this is quite a smart move but also opportunistic in which they are able to gain the benefits from Indonesia's resources so that they are able to gain a few favors for themselves in the future as well.

Alongside from that aspect, there are also negative points derived from this program as well. Firstly, one of the things that lacks in the program of FOI is the schedule that was tightly packed to be conducted. Although the purpose is to use the full time possible in showcasing Indonesia's sides in any way however it would be a waste if the participants were not given time for self-learning and self-exploring deeper into Indonesian communities. It would be one of the greatest chance for the young diplomats to have deeper sense of connection to the Indonesian people when they are able to see the part that the institution does not show them to see directly, so that engagement by the participants to more non-state actors can create better form of public diplomacy. Secondly, there is a lack of effort in maintaining communication in the post-program activities. The institution sees that once the program ended, the form of personal agendas and memories as well as ceremonies seemed enough for the public diplomacy to be carried out, however this is where the lack of push by the Indonesian performance on public diplomacy lacks very much which is the maintenance of connecting the communication bridge with the involved participants of this program. It would seem that the MoFA believes that there is no need for more effort in the aftermath of the program because the schedule of the program was just enough but that is clearly not the point of the public diplomacy carried out.

Based on the concept of Mark Leonard's three dimension of public diplomacy, included three dimensions that connected to this analysis. Although the three dimensions can be as vastly important, the writer would like to specify mostly on the dimension of relationship building. While analyzing though the dimensions of News Management and Strategic Communication, there are several key point activities accomplished such as the participants of FOI created personal agenda in order to send out their information gathering and analysis of Indonesia to their own respective foreign ministries and also where media comes into play along in creating news articles about this program to several online media in order to bring attention of this form of public diplomacy activities towards Indonesia and foreign countries to showcase Indonesia's efforts in maintaining the image. However, it fails to deliver the timing of delivering these messages as it is appearing in very little of attention in result and the institution do not seem to boast about the development of the 
program for further communication much so it does fail to conduct as a whole since there is less effort in reaching for better understanding.

For relations building it is very important to note it involves three spheres which are political/military, economic, societal/cultural, which are brought up through the public diplomacy acts of introducing these spheres to the young diplomats participated. However, there were less effort of creating a long term effect based off of this program in further on trying to follow up through communication. As mentioned before, the lack of effort to push for the communication build up after the program ended do not seem to be in the plan-making of the procedure when clearly the aftermath communication is the most important fact to be conducted after the public diplomacy carried out.

It would seem to lost the value of "building relations" when there is no progress of the post-program networks. When no communication follow-up appeared then it would be very likely that the connections between the young diplomats to Indonesia would dimmed out in the future as it serves no more interest for their own benefits, just solely due to the lack of communication from Indonesia's part. Another information regarding to this finding that it would seem very short of Indonesian MoFA to not round up their efforts further on by indulging more time on communication in the post-program rather just solely focusing on the implemented program occurs. Rather than just holding out programs, the institution should also carry out more resources by acting as intel by the available diplomats from the MoFA to participate in other countries' programs and not just creating them. Obtaining networks by participating is also very opportunistic for national interests as well, especially when it comes to serve from government to diplomats directly.

\section{CONCLUSION}

In the overall view, public diplomacy involves actors, primarily state actors, in the attempt to achieve for their interests through various degrees of peaceful activities, usually through many examples of different activities such as exchange of culture, international fairs, music and food festivals, films and others. The focus of public diplomacy implemented by Indonesia highlights on the instruments of political and cultural exchange as the best strategy carried out is through exchanges of ideas, values, and culture.Friends of Indonesia: Fellowship for Future Ambassadors 2018 is a program of Indonesia's public diplomacy, created to invite 10 young diplomats from 10 different countries to visit Indonesia for 2 weeks in order to learn about Indonesia through people-to-people contact, furthermore to bond closer with the diplomats from 10 different countries in understanding Indonesia intimately.

Based on the findings, FOI maintained the bridge of relations between Indonesia and the young diplomats from different 10 countries and were able to showcase and exchange information of Indonesia's aspects of politics, economy, and social-culture however based on the analysis, it failed to conduct further communication follow-up after the program ended resulting in weak of relationship building in the form of public diplomacy carried out by Indonesia. Suggestions for future references in case 
another program like this would occur, it is highly advisable to maintain communication after public diplomacy activities ended in which the connection between actors would not weaken in time.

\section{BIBLIOGRAPHY}

Azra, Azyumardi. 2015. "Indonesia's middle power public diplomacy: Asia and Beyond." In Understanding Public Diplomacy in East Asia: Middle Powers in a Troubled Region, by YulSohn Jan Melissen (Ed.), 131-154. New York: Palgrave MacMillan.

KementrianLuarNegeriRepublik Indonesia, DirektoratDiplomasiPublik (https: / /www.kemlu.go.id/id/tentang-kemlu/struktur-

kemlu/organization.aspx?kementerianid=6), accessed on 10th September 2018.

Leonard, Mark. 2005. "Public Diplomacy", London, The Foreign Policy Centre.

Melissen, Jan. 2005. The New Public Diplomacy: Soft Power in International Relations. New York: Palgrave Macmillan.

PeraturanMenteriLuarNegeriRepublik Indonesia Nomor 56 Tahun 2015, (https://pih.kemlu.go.id/files/PERPRES_56_2015_KEMENTERIAN_LUAR_NEGE RI.pdf) accessed on 10th September 2018.

R. Fitzpatrick Kathy. 2017."Public Diplomacy in the Public interest".Journal of Public Interest Communications.

Snow Nancy \& Taylor M. Phillip. 2009."RoutledgeHandbook of Public Diplomacy". New York: Routledge.

Sukma, Rizal. 2011. "Soft Power and Public Diplomacy: The Case of Indonesia." In Public Diplomacy and Soft Power in East Asia, by Jan MelissenSook Jong Lee, 91 - 116. New York: Palgrave Macmillan.

Tobing Jakob, Getting to Democracy in the World's largest Muslim Country: How Indonesia Did It., Insititute for Advanced Studies in Culture, (https://s3.amazonaws.com/iascprod/uploads/pdf/66cfa7c8576b4c749b3f.pdf), accessed on 5th September 2018.

Yadika Bawono, Menkeu: RI Jadi Negara denganPerekonomianTerbesar ke-5 di Dunia, Liputan 6, 3 February 2018, (https://www.liputan6.com/bisnis/read/3253728/menkeu-ri-jadi-negaradengan-perekonomian-terbesar-ke-5-di-dunia), accessed on 5 th September 2018. 